\title{
Azadirachta indica ethanolic extract protects neurons from apoptosis and mitigates brain swelling in experimental cerebral malaria
}

\author{
Selma Bedri ${ }^{1}$, Eltahir A Khalil', Sami A Khalid ${ }^{1}$, Mohammad A Alzohairy ${ }^{3}$, Abdlmarouf Mohieldein $^{3}$, \\ Yousef H Aldebasi ${ }^{4}$, Paul Faustin Seke Etet ${ }^{5}$ and Mohammed Farahna ${ }^{5^{*}}$
}

\begin{abstract}
Background: Cerebral malaria is a rapidly developing encephalopathy caused by the apicomplexan parasite Plasmodium falciparum. Drugs currently in use are associated with poor outcome in an increasing number of cases and new drugs are urgently needed. The potential of the medicinal plant Azadirachta indica (Neem) for the treatment of experimental cerebral malaria was evaluated in mice.

Methods: Experimental cerebral malaria was induced in mice by infection with Plasmodium berghei ANKA. Infected mice were administered with Azadirachta indica ethanolic extract at doses of 300, 500, or $1000 \mathrm{mg} / \mathrm{kg}$ intraperitoneally (i.p.) in experimental groups, or with the anti-malarial drugs chloroquine $(12 \mathrm{mg} / \mathrm{kg}$, i.p.) or artemether $(1.6 \mathrm{mg} / \mathrm{kg}$, i.p.), in the positive control groups. Treatment was initiated at the onset of signs of brain involvement and pursued for five days on a daily basis. Mice brains were dissected out and processed for the study of the effects of the extract on pyramidal cells' fate and on markers of neuroinflammation and apoptosis, in the medial temporal lobe.
\end{abstract}

Results: Azadirachta indica ethanolic extract mitigated neuroinflammation, decreased the severity of brain oedema, and protected pyramidal neurons from apoptosis, particularly at the highest dose used, comparable to chloroquine and artemether.

Conclusions: The present findings suggest that Azadirachta indica ethanolic extract has protective effects on neuronal populations in the inflamed central nervous system, and justify at least in part its use in African and Asian folk medicine and practices.

Keywords: Cerebral malaria, Azadirachta indica extract, Pyramidal neurons, Neuroinflammation, Brain oedema

\section{Background}

Cerebral malaria is a rapidly developing encephalopathy that represents the most severe neurological complication of infection with Plasmodium falciparum. Cerebral malaria mainly occurs in resource-poor tropical countries, and mostly affects children [1,2]. Surviving patients display neurologic and cognitive deficits, including consciousness impairment, cerebellar ataxia, seizures, and coma, making cerebral malaria a major cause of childhood neurodisability in endemic areas

\footnotetext{
* Correspondence: farahnamohammed@hotmail.com

${ }^{5}$ Department of Basic Health Sciences, College of Applied Medical Sciences, Qassim University, Buraydah 51452, Saudi Arabia

Full list of author information is available at the end of the article
}

[3-6]. The pathogenesis of neuro-cognitive sequelae is poorly understood.

Experimental models of cerebral malaria have been providing new mechanistic insights that will help develop efficient neuro-protective interventions. The nonhuman pathogenic parasite Plasmodium berghei has been used to induce experimental cerebral malaria in mice that has some features comparable to the human disease [7-9]. Experimental evidence suggests that the vast array of pro-inflammatory molecules released by the host to fight the infection and alterations due to parasite sequestration in the microvessels cause leakage of plasma into the parenchyma resulting in brain oedema, and may contribute to the subsequent blood-brain 
barrier breakdown [10,11]. Brain parenchyma infiltration by danger or pathogen-associated molecules would trigger a sustained detrimental neuroinflammatory response leading to the recruitment of circulating immune cells. The latter cells would induce death through cell-mediated apoptosis in sensible neuronal populations, by triggering pathways such as caspase 3 and Fas-Fas ligand [12-14]. Previous studies and reports have shown that such inflammation-triggered apoptosis can induce cerebellar ataxia when affecting Purkinje cells in the cerebellum [15-17]. Similarly, apoptosis affecting cortical neurons may explain many other neurologic deficits observed in experimental cerebral malaria, such as cognitive impairment or seizures [18-21]. Overall, these findings corroborate the alterations reported in humans $[9,14,22,23]$. New effective drugs are urgently needed for cerebral malaria treatment due to the development of parasite chemoresistance, and to improve current drugs' poor treatment outcome [24-26].

Azadirachta indica is a plant commonly used in the African and Asian folk medicine and practices [27-31]. Anti-malarial effects of $A$. indica extracts have been demonstrated [32-36], as well as the neuro-protective effects on Purkinje cells of $P$. berghei-infected mice successfully mitigating cerebellum malaria [16]. The present study addresses the potential of $A$. indica extract for the protection of cortical and sub-cortical pyramidal neurons of $P$. berghei-infected mice, considering the implications for the treatment of cerebral malaria-associated cortical deficits.

\section{Methods}

\section{Experimental procedure}

Thirty five mice, divided into seven groups (five animals per group), were used in this study. These groups were: i) a disease control group made of untreated $P$. bergheiinfected mice; ii) two positive control groups made of $P$. berghei-infected mice treated with the commercially available anti-malarial drugs chloroquine $(12 \mathrm{mg} / \mathrm{kg}$ in distilled water, i.p.) and artemether $(1.6 \mathrm{mg} / \mathrm{kg}$ in olive oil, i.p.); iii) three experimental groups made of $P$. bergheiinfected mice treated with $A$. indica ethanolic extract at doses 300,500 , or $1000 \mathrm{mg} / \mathrm{kg}$ (i.p.); iv) and a group of uninfected healthy animals. Parasitaemia, body weight, core body temperature, and signs of brain involvement were monitored. Treatment was started when the number of parasitized red blood cells was $>5 \%$ (severe malaria indicator) and was associated with signs of brain involvement. Treatment was pursued for five days on a daily basis. Mice either died spontaneously or were sacrificed by ether inhalation-induced deep anesthesia once signs of disease terminal stage (hypothermia, ptosis, and convulsion) [37], were observed. Uninfected mice were sacrificed concomitantly with the last animals to check for disease terminal stage signs. For all animals, brains were dissected out and processed for histopathological analysis.

\section{Animals and infection}

Male Swiss albino mice (weighing $26.5 \pm 3.0$ g, aged $6 \pm$ 1 week) were donated by Sudan National Health Laboratory (Khartoum, Sudan). Mice were maintained at a 12:12 light/dark cycle and were given ad libitum access to food (standard diet) and water. For infection, mice were administered (i.p.) with a load of $10 \times 10^{6}$ parasitized red blood cells containing $P$. berghei ANKA. The parasitaemia was checked by blood smear Giemsa-staining. All procedures received approval from the Ethical Committee of the Institute of Endemic Diseases of the University of Khartoum and animals were handled according to institutional guidelines. Plasmodium berghei ANKA blood-stage cryostabilates were kindly donated by Dr. C.R. Pillai (National Institute of Malaria, New Delhi, India).

\section{Preparation of the extract}

Fresh leaves of $A$. indica were collected in Khartoum region, where they are commonly used in folk medicine to treat malaria [33], and shade-dried. Dry leaves were grinded, and $1500 \mathrm{~g}$ of powder were macerated in $15 \mathrm{~L}$ of ethanol for three consecutive days at room temperature. A $1 \mathrm{mg} / \mathrm{mL}$ stock solution was obtained by filtration and boiling of the supernatant, and was stored at $4^{\circ} \mathrm{C}$ until use. Three doses of $A$. indica, i.e. 300, 500, and $1,000 \mathrm{mg} / \mathrm{kg}$, were administered to the respective experimental groups once a day for five days. These regimens were chosen in accordance with previous pharmacological studies in malaria models $[16,28]$.

\section{Pyramidal neuron density and brain oedema}

Brains dissected out were fixed in 10\% neutral buffered formaldehyde, then paraffin-embedded and cut sagittally (section thickness: $5 \mu \mathrm{m}$ ). Sections were deparaffinized in xylene, rehydrated, and processed for haematoxylineosin (H\&E) staining. The pyramidal neuron volumetric density, i.e. the proportion of brain subfield that is occupied by pyramidal neuronal cell bodies, was determined as described by Highley and colleagues [38]. Pyramidal neurons were counted on five consecutive sections, in the medial temporal lobe, using a light microscope with a fixed $1 \mathrm{~cm}$ grid eyepiece under $40 \times$ objective. Brain oedema was assessed by giving a severity score integrating histopathological parameters, such as the importance (how big) and frequency (how numerous) of fluid built up in the brain parenchyma, on the H\&E stained sections $[39,40]$.

\section{Immunohistochemistry}

The sections processed for immunohistochemical labeling were deparaffinized in xylene, rehydrated, and endogenous 


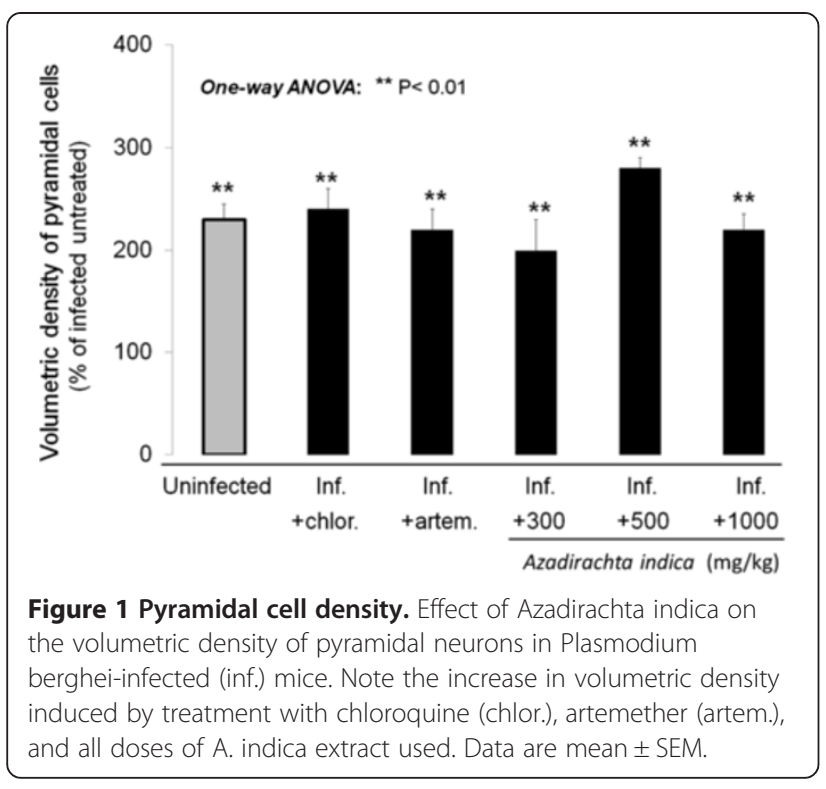

peroxidase activity was extinguished. Sections were then pre-incubated in normal serum buffer solution (Diagnostic BioSystems, Serpentine, CA, USA), and incubated for $3 \mathrm{~h}$ in either rabbit anti-caspase-3, anti-FAS, anti-FAS ligand, anti-tumor necrosis factor (TNF), or anti-nitric oxide synthase (NOS) primary antibody buffer solution (dilution factor 1:40, Lica Biosystem Newcastle Ltd, UK), followed by a biotinylated secondary antibody and streptavidinconjugated horseradish peroxidase (Vision Biosystems Novocastra, Novocastra Laboratories Ltd., Newcastle, UK) prepared according to the kit instructions. The sections were incubated with 3,3'-diaminobenzidine hydrochloride (DAB) chromogen substrate (Vision Biosystems Novocastra) according to the manufacturer's instructions, and counterstained with H\&E. P value $<.05$ was considered significant. Thorough washes between steps were performed using immune wash buffer (Vision Biosystems Novocastra). Sections were dehydrated through a graded ethanol series, cleared in xylene, and covered with a thin glass coverslip. The fraction of pyramidal neurons expressing each of the studied markers, i.e. the markers of apoptosis caspase 3, Fas, and Fas ligand, and the markers of neuroinflammation-triggered apoptosis TNF and NOS, was determined using a light microscope under $40 \times$ objective.

\section{Statistical analysis}

Data obtained from infected treated or uninfected groups were compared to those obtained from the infected untreated group using one-way ANOVA followed by LSD

\section{A Neurons expressing caspase 3 Neurons +Caspase 3}

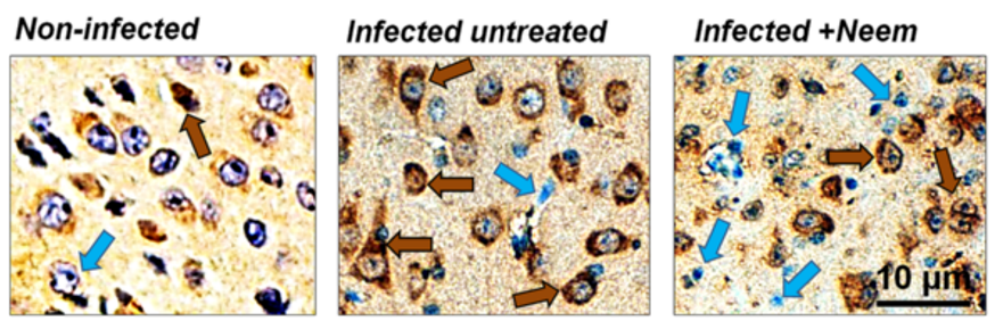

\section{B Number of neurons expressing caspase 3}

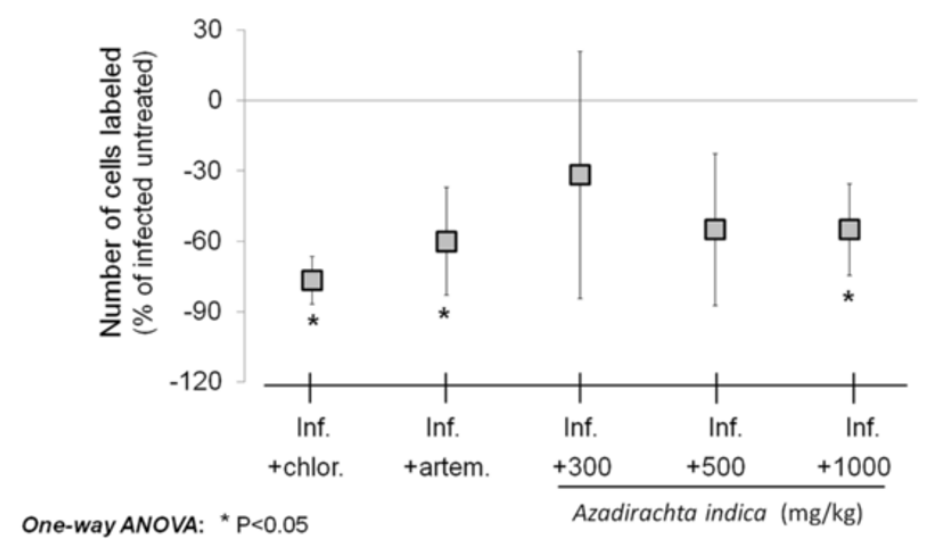

Figure 2 Caspase 3 expression. A. Micrographs showing the expression of caspase 3 in pyramidal neurons of representative examples of (from left): an uninfected mouse, an untreated Plasmodium berghei-infected mouse (inf.), and a P. berghei-infected mouse treated with Azadirachta indica crude extract. B. Effect of $\mathbf{A}$. indica on caspase 3 expression in pyramidal neurons of P. berghei-infected mice. Note the significant decrease following treatment with chloroquine (chlor.), artemether (artem.), and $\mathbf{A}$. indica extract (dose 1,000 mg/kg). Data are mean \pm SEM. 
test. Differences with a $\mathrm{p}$ value $<.05$ were considered statistically significant. All data were expressed as a percentage of the value obtained in the infected untreated group. Data are presented as mean $\pm \operatorname{SEM}(n=5)$.

\section{Results}

\section{General observations}

The early signs of disease started five days after infection in the majority of $P$. berghei-infected animals, i.e. in the disease control group and in animals treated with chloroquine, artemether, or one of the three doses of A. indica extract. Cerebral malaria signs appeared at day $6 \pm 1$ post-infection. The most recurrent ones were a ruffled fur, locomotor impairments, and sickness behavior (anorexia, cachexia, fever) associated with body weight loss. Animals treated with $A$. indica, chloroquine or artemether did not displayed fever (as evaluated by increases in core body temperature), and from dose $500 \mathrm{mg} / \mathrm{kg}$ of extract locomotor disturbances and body weight loss were improved. Parasitaemia was decreased in infected mice following treatment with chloroquine or arthemether (from $6.1 \pm 1.8 \%$ to $1.2 \pm 0.4 \%, \mathrm{P}<0.05$ ), but no significant change was observed in $A$. indica-treated animals, as previously reported [16].

Azadirachta indica extract did not protected infected mice from death, unlike chloroquine and artemether, although the highest doses slightly (not significantly) delayed death time. Infected untreated mice spontaneously died at day $9 \pm 1$ post-infection, $A$. indica-treated mice treated with the highest doses started to die at day 11, whereas no animal died in groups treated with chloroquine and artemether during the time of observation.

\section{A Neurons expressing FAS}

\section{Neurons +Fas}

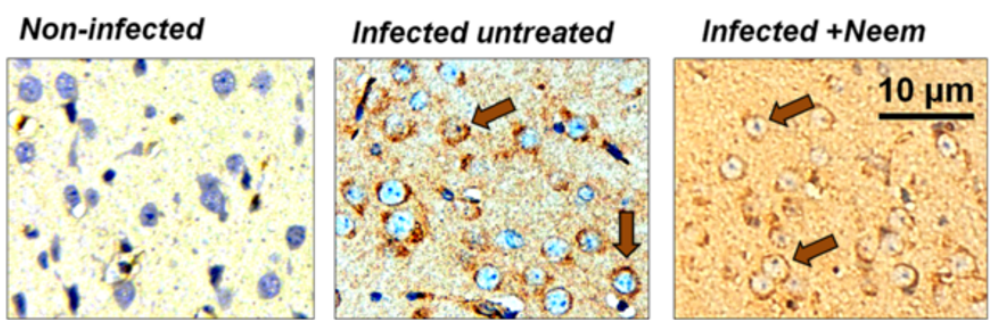

B Number of neurons expressing Fas or its ligand

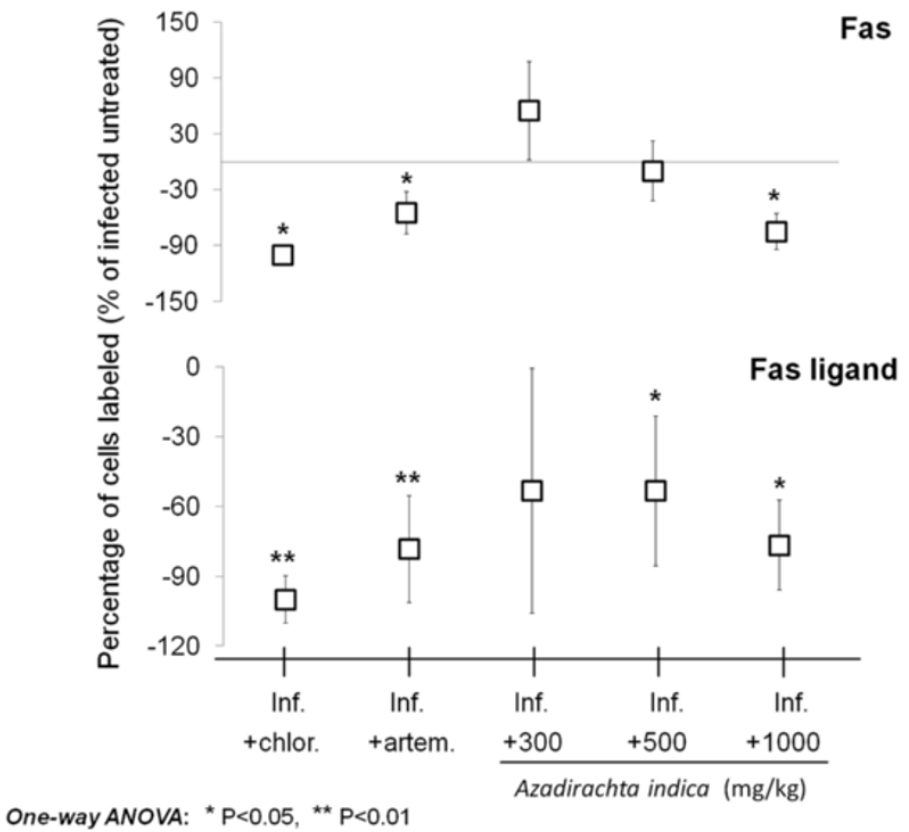

Figure 3 Fas and Fas ligand expression. A. Micrographs showing the expression of Fas in pyramidal neurons of representative examples of (from left): an uninfected mouse, an untreated Plasmodium berghei-infected mouse (inf.), and a P. berghei-infected mouse treated with Azadirachta indica crude extract. B. Effect of A. indica on the expression of Fas (upper) and Fas ligand (lower) in pyramidal neurons of P. bergheiinfected mice. Note the significant decrease in expression of both molecules following treatment with chloroquine (chlor.), artemether (artem.), and $\mathbf{A}$. indica extract (more marked at dose $1,000 \mathrm{mg} / \mathrm{kg}$ ). Data are mean $\pm \mathrm{SEM}$. 
However, about all the survivors in groups treated with the extract were sacrificed two days after (day 13 postinfection) as terminal signs of cerebral malaria, i.e. hypothermia, ptosis, ataxia, and convulsion, were observed. All other animals, including those treated with chloroquine or artemether as well as uninfected ones were also sacrificed then.

\section{Extract effect on pyramidal neuron density}

The effect of $A$. indica on $P$. berghei-infected mice pyramidal neuron volumetric density is shown in Figure 1. The volumetric density of pyramidal neurons of mice treated with $A$. indica extract was significantly higher at all doses, in comparison to the infected untreated group $(\mathrm{P}<0.01)$, and was comparable (non-significantly different [41]) to the values observed in the infected groups treated with chloroquine or artemether, and to uninfected group values, which were also significantly different from infected untreated group values $(\mathrm{P}<0.01$ for all three groups).

\section{Extract effect on caspase 3 expression}

The effect of $A$. indica on the expression of caspase 3 in pyramidal neurons of $P$. berghei-infected mice is shown in Figure 2. Pyramidal neurons of mice treated with
A. indica extract displayed a significant decrease in caspase 3 expression at the highest dose, in comparison to the infected untreated group $(\mathrm{P}<0.05)$, comparable to the decreases induced by chloroquine $(\mathrm{P}<0.05 v s$. infected untreated group) or artemether $(\mathrm{P}<0.05$ vs. infected untreated group).

\section{Extract effect on Fas and Fas ligand expression}

The effect of $A$. indica on Fas and Fas ligand expression in $P$. berghei-infected mice pyramidal neurons is shown in Figure 3. Pyramidal neurons of mice treated with $A$. indica extract displayed a significant decrease in Fas expression at the highest dose, in comparison to the infected untreated group $(\mathrm{P}<0.05)$ and a decrease in Fas ligand expression at doses 500 and $1000 \mathrm{mg} / \mathrm{kg}(\mathrm{P}<0.05$ vs. infected untreated group). The significant decreases observed were comparable to those induced by chloroquine $(\mathrm{P}<0.05$ for Fas and $\mathrm{P}<0.01$ for Fas ligand $v s$. infected untreated group) or artemether $(\mathrm{P}<0.05$ for Fas and $\mathrm{P}<0.01$ for Fas ligand $v s$. infected untreated group).

\section{Extract effect on TNF expression}

The effect of $A$. indica on TNF expression in pyramidal neurons of $P$. berghei-infected mice is shown in Figure 4.

\section{A Neurons expressing TNF Neurons +TNF}

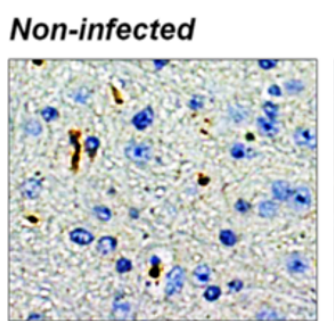

Infected untreated
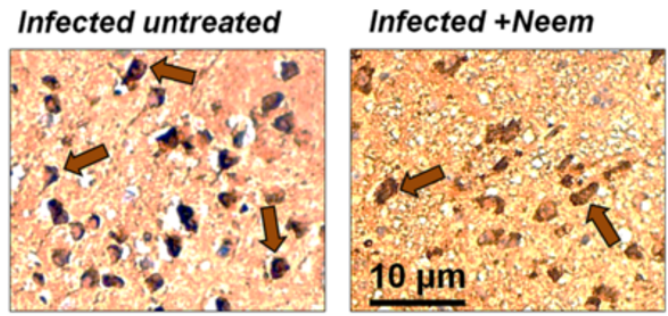

\section{B Number of neurons expressing TNF}

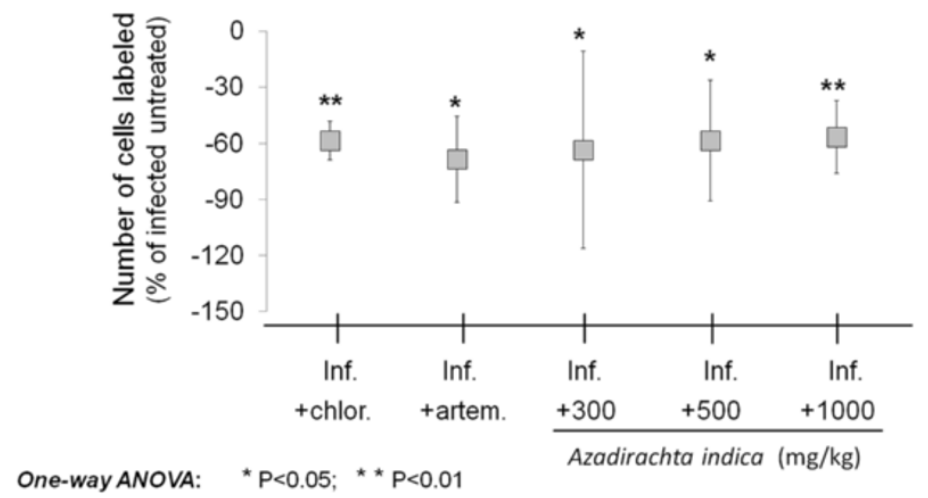

Figure 4 TNF expression. A. Micrographs showing the expression of tumor necrosis factor (TNF) in pyramidal neurons of representative examples of (from left): an uninfected mouse, an untreated Plasmodium berghei-infected mouse (inf.), and a P. berghei-infected mouse treated with Azadirachta indica crude extract. B. Effect of $\mathbf{A}$. indica on the expression of TNF in pyramidal neurons of P. berghei-infected mice. Note the significant decrease in expression following treatment with chloroquine (chlor.), artemether (artem.), or any of the doses of $\mathbf{A}$. indica extract used. 
Pyramidal neurons of mice treated with $A$. indica extract displayed a significant decrease in TNF expression at all doses used, in comparison to the infected untreated group $(\mathrm{P}<0.01$ at $1000 \mathrm{mg} / \mathrm{kg}$ ). This effect was comparable to the decrease in TNF expression induced by chloroquine $(\mathrm{P}<0.01$ vs. infected untreated group) or artemether $(\mathrm{P}<0.05$ vs. infected untreated group $)$.

\section{Extract effect on NOS expression}

The effect of $A$. indica on the expression of NOS in $P$. berghei-infected mice pyramidal neuron is shown in Figure 5. Azadirachta indica extract induced a significant decrease in NOS expression, in comparison to the infected untreated group. However, such decrease was statistically significant and comparable to the effect of chloroquine $(\mathrm{P}<0.05$ vs. infected untreated group $)$ or artemether $(\mathrm{P}<0.05$ vs. infected untreated group) only at the highest dose used $(1000 \mathrm{mg} / \mathrm{kg}, \mathrm{P}<0.05)$.

\section{Extract effect on brain oedema severity}

The effect of $A$. indica extract on brain oedema severity in P. berghei-infected mice is shown in Figure 6. Azadirachta indica extract induced a significant decrease in brain oedema severity at all doses used, in comparison to the infected untreated group $(\mathrm{P}<0.05)$, which was comparable to the effect of chloroquine $(\mathrm{P}<0.01 v s$. infected untreated group $)$ or artemether $(\mathrm{P}<0.05$ vs. infected untreated group).

\section{Discussion}

The present study points out the protective effects of $A$. indica extract on pyramidal neurons in experimental cerebral malaria induced by $P$. berghei-infection in mice.

\section{Protective effects on pyramidal neurons}

Pyramidal neuron density study revealed comparable values between $P$. berghei-infected mice treated with the extract of $A$. indica and uninfected mice, which were significantly different from untreated $P$. berghei-infected mice (disease control group) where a significant decrease in pyramidal neuron density, characteristic of cerebral malaria insult $[14,18-20]$, was observed. These findings suggest that the extract protected pyramidal neurons from cerebral malaria-induced apoptosis. In order to further characterize these effects, the expression of apoptosis markers was studied, considering the importance of this phenomenon in cerebral malaria-associated encephalopathy [7-9].

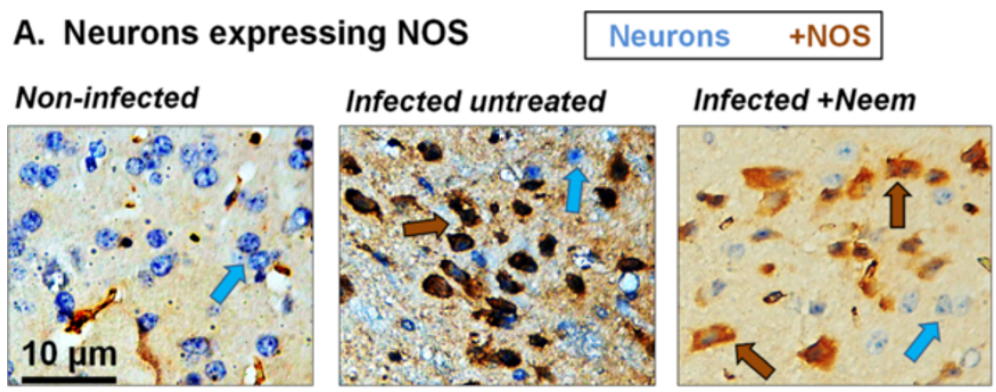

\section{B. Number of neurons expressing NOS}

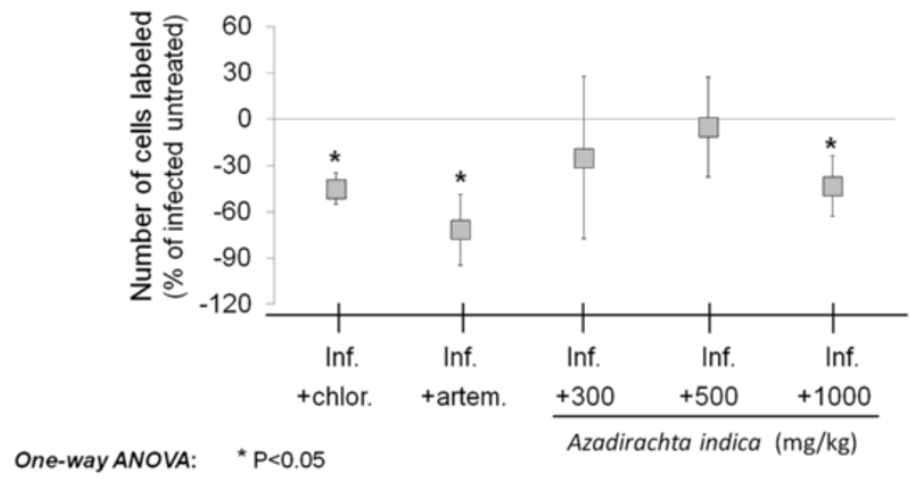

Figure 5 NOS expression. A. Micrographs showing the expression of nitric oxide synthase (NOS) in pyramidal neurons of representative examples of (from left): an uninfected mouse, an untreated Plasmodium berghei-infected mouse (inf.), and a P. berghei-infected mouse treated with Azadirachta indica crude extract. B. Effect of $\mathbf{A}$. indica on the expression of NOS in pyramidal neurons of P. berghei-infected mice. Note the significant decrease in expression following treatment with chloroquine, artemether, and $\mathbf{A}$. indica extract highest dose. Data are mean \pm SEM. 


\section{A Representative case with the highest brain edema severity score}

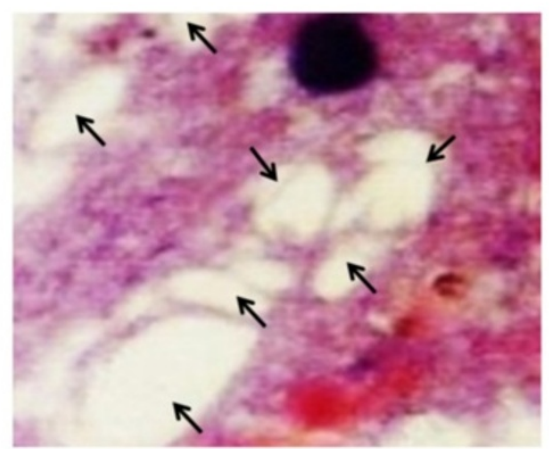

A severity score of brain edema was given on the basis of the importance and frequency of fluid builtup in the brain parenchyma

₹ Fluid builtup

\section{B Severity of brain edema}

One-way ANOVA: ${ }^{*} \mathrm{P}<0.05 \quad{ }^{*}{ }^{*} \mathrm{P}<0.01$

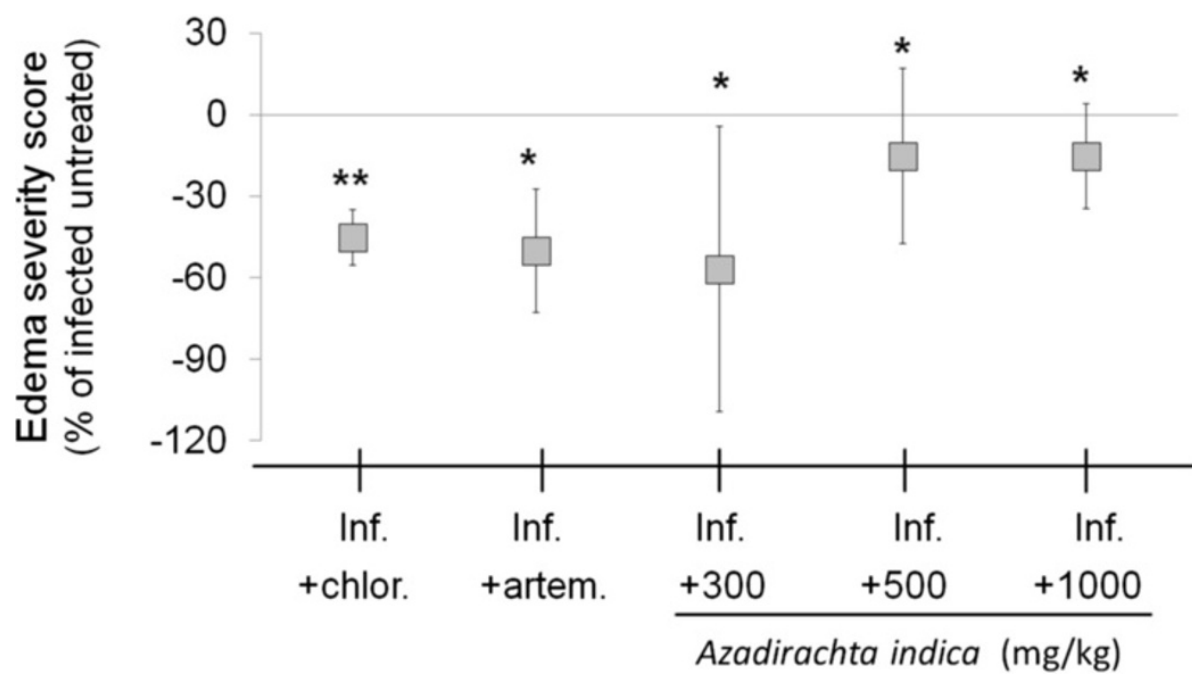

Figure 6 Brain oedema. A. Micrograph showing a representative case of highest brain oedema severity score. B. Effect of Azadirachta indica on the severity of brain oedema in Plasmodium berghei-infected (inf.) mice. Note the significant decrease in brain oedema severity following treatment with chloroquine (chlor.), artemether (artem.), or any of the doses of $\mathbf{A}$. indica extract used. Data are mean \pm SEM.

Striking decrease in the expression of apoptosis markers The markers of apoptosis studied were caspase 3, Fas, and Fas ligand, which are commonly used for the detection of apoptosis in neuronal populations $[13,19]$. Azadirachta indica extract induced a striking decrease in caspase 3, Fas, and Fas ligand expressions on pyramidal neurons of $P$. berghei-infected mice, particularly at the highest dose used. Considering that these markers are associated with the risk for neuron apoptosis [13,19], the present finding indicates that $A$. indica extract has anti-apoptotic effects on pyramidal neurons in experimental cerebral malaria. The latter effects probably account for at least part of the protective effects of the extract against pyramidal neuron death in treated $P$. berghei-infected mice.
Considering that the pro-inflammatory environment, and particularly infiltrating immune cells, contribute to the detrimental effects of cerebral malaria on neurons, including apoptosis in sensible neuronal populations [12,14,42], through extrinsic mediators of apoptosis such as TNF and NOS $[12,43,44]$, we have addressed the effect of $A$. indica extract on these inflammatory triggers of apoptosis in $P$. berghei-infected mice.

\section{Mitigation of neuroinflammatory triggers of apoptosis} and brain oedema severity

Treatment with $A$. indica extract induced decreases in pyramidal neuron expression of TNF and NOS in P. bergheiinfected mice as compared with disease control group, 
suggesting that the extract modulated inflammation in the brain parenchyma. Besides, considering that brain oedema is a major causative of the inflammatory response in the brain parenchyma (through infiltrating danger or pathogen-associated molecules $[10,11])$, the decrease in oedema severity observed in groups treated with the extract in the present study, indicate that the aforementioned anti-inflammatory effects may be mediated, at least in part, by protective effects on brain vessels. These findings are in agreement with our precedent observations in Purkinje cells of $P$. berghei-infected mice, where $A$. indica also displayed neuroprotective effects [16]. Comparable effects of $A$. indica extract have been reported in other models of detrimental neuroinflammation associated with brain oedema, including cerebral post-ischemic reperfusion and hypoperfusion in rats $[45,46]$. Thus, the findings herein reported confirm that $A$. indica extract has neuroprotective effects in experimental cerebral malaria, and indicate that such effect may be mediated through protective effects on brain vessels and the consequent decrease in neuroinflammation severity. Not surprisingly and interestingly, chloroquine and artemether, drugs in use for cerebral malaria treatment in the field [37,47], also induced similar effects, corroborating their beneficial effects reported in humans, and pointing out at least part of the mechanisms accounting for these effects. It appears, therefore, that future studies aiming at unraveling the active principle(s) accounting for the beneficial effects of $A$. indica extract reported may provide key elements for the development of new drugs for cerebral malaria. Subjecting the bioactive agents of Azadirachta indica which have already been characterized, such as gedunin [33, 48], to a similar study may provide better insights into the neuroprotective effects herein described.

\section{Conclusions}

Azadirachta indica extract did not protected infected mice from death from cerebral malaria, although the highest doses slightly delayed death time. However, $A$. indica extract displayed neuroprotective effects mediated probably by mitigating oedema build up, and modulating both neuroinflammatory triggers of apoptosis and apoptosis signaling pathways. The use of extracts of $A$. indica in African and Asian folk medicine and practices for the treatment of malaria and cerebral malaria is justified. Characterization of the active principle(s) accounting for these effects will probably provide new drugs, which are particularly needed in the current context of increased chemoresistance to chloroquine.

\section{Competing interests}

The authors declare that they have no competing interests.

\section{Authors' contributions}

$M F, E A K, S A K, M A A, A M, P F S E$, and YHA participated in the design of the experiment. SB and MF performed the experiments. MF, EAK, SAK, MAA, AM,
SB, YHA and PFSE participated in the preparation of the manuscript. MF and PFSE analysed the data, prepared the figures, and were in charge of the manuscript submission. All authors read and approved the final manuscript.

\section{Acknowledgements}

The authors would like to acknowledge the Qassim University and Ministry of Higher education for funding this project as well as Dr. C. R. Pillai, National Malaria Institute, New Delhi, India for donation of the parasite. The authors would like to acknowledge the critical thinking and brainstorming of Professor Mustafa Idris. The authors would like to acknowledge the help of Dr. Imran Ulhag for providing a second opinion in analyzing the immunohistochemistry results; the technical support of Ali Yousif, Mohammed Awad and Said Yousif in the study and the help of Dr. Mohsin Shaik and Dr. Mgdy Abdelsalam in the statistical analysis.

Special thanks are due to the Institute of Endemic Diseases of the University of Khartoum and to the College of Applied Medical Sciences of Qassim University for the logistic support, and to Prof. Bunyamin Shahin for his insightful suggestions.

\section{Author details}

${ }^{1}$ Department of Clinical Pathology and Immunology, Institute of Endemic Diseases, University of Khartoum, Khartoum, Sudan. ${ }^{2}$ Department of Pharmacognosy, Faculty of Pharmacy, University of Khartoum, Khartoum, Sudan. ${ }^{3}$ Department of Laboratory Medicine, College of Applied Medical Sciences, Qassim University, Buraydah 51452, Saudi Arabia. ${ }^{4}$ Department of Optometry, College of Applied Medical Sciences, Qassim University, Buraydah 51452, Saudi Arabia. ${ }^{5}$ Department of Basic Health Sciences, College of Applied Medical Sciences, Qassim University, Buraydah 51452, Saudi Arabia.

Received: 1 February 2013 Accepted: 20 August 2013

Published: 29 August 2013

\section{References}

1. Mishra SK, Newton CR: Diagnosis and management of the neurological complications of falciparum malaria. Nat Rev Neurol 2009, 5:189-198.

2. Idro R, Marsh K, John CC, Newton CR: Cerebral malaria: mechanisms of brain injury and strategies for improved neurocognitive outcome. Pediatr Res 2010, 68:267-274.

3. Idro R, Ndiritu M, Ogutu B, Mithwani S, Maitland K, Berkley J, Crawley J, Fegan G, Bauni E, Peshu N, Marsh K, Neville B, Newton C: Burden, features, and outcome of neurological involvement in acute falciparum malaria in Kenyan children. JAMA 2007, 297:2232-2240.

4. Kihara M, Carter JA, Holding PA, Vargha-Khadem F, Scott RC, Idro R, Fegan GW, de Haan M, Neville BG, Newton CR: Impaired everyday memory associated with encephalopathy of severe malaria: the role of seizures and hippocampal damage. Malar J 2009, 8:273.

5. Kariuki SM, Ikumi M, Ojal J, Sadarangani M, Idro R, Olotu A, Bejon P, Berkley JA, Marsh K, Newton CR: Acute seizures attributable to falciparum malaria in an endemic area on the Kenyan coast. Brain 2011, 134:1519-1528.

6. Gwer S, Thuo N, Idro R, Ndiritu M, Boga M, Newton C, Kirkham F: Changing trends in incidence and aetiology of childhood acute non-traumatic coma over a period of changing malaria transmission in rural coastal Kenya: a retrospective analysis. BMJ Open 2012, 2:e000475.

7. Kaiser K, Texier A, Ferrandiz J, Buguet A, Meiller A, Latour C, Peyron F, Cespuglio R, Picot S: Recombinant human erythropoietin prevents the death of mice during cerebral malaria. J Infect Dis 2006, 193:987-995.

8. Combes V, Coltel N, Faille D, Wassmer SC, Grau GE: Cerebral malaria: role of microparticles and platelets in alterations of the blood-brain barrier. Int J Parasitol 2006, 36:541-546.

9. Faille D, El-Assaad F, Alessi MC, Fusai T, Combes V, Grau GE: Plateletendothelial cell interactions in cerebral malaria: the end of a cordial understanding. Thromb Haemost 2009, 102:1093-1102.

10. Pino P, Taoufiq Z, Nitcheu J, Vouldoukis I, Mazier D: Blood-brain barrier breakdown during cerebral malaria: suicide or murder? Thromb Haemost 2005, 94:336-340.

11. Bisser S, ON O-M-O-B, Toure FS, Taoufiq Z, Bouteille B, Buguet A, Mazier D: Harbouring in the brain: a focus on immune evasion mechanisms and their deleterious effects in malaria and human African trypanosomiasis. Int J Parasitol 2006, 36:529-540.

12. Lovegrove FE, Gharib SA, Patel SN, Hawkes CA, Kain KC, Liles WC: Expression microarray analysis implicates apoptosis and interferon- 
responsive mechanisms in susceptibility to experimental cerebral malaria. Am J Pathol 2007, 171:1894-1903.

13. Lackner P, Burger C, Pfaller K, Heussler V, Helbok R, Morandell M, Broessner G, Tannich E, Schmutzhard E, Beer R: Apoptosis in experimental cerebral malaria: spatial profile of cleaved caspase- 3 and ultrastructural alterations in different disease stages. Neuropathol Appl Neurobiol 2007, 33:560-571.

14. Toure FS, Ouwe-Missi-Oukem-Boyer O, Bisvigou U, Moussa O, Rogier C, Pino $P$, Mazier D, Bisser S: Apoptosis: a potential triggering mechanism of neurological manifestation in Plasmodium falciparum malaria. Parasite Immunol 2008, 30:47-51.

15. Teo JT, Swayne OB, Silber E: Cerebellar ataxia after malaria. Neurology 2009, 73:73-74.

16. Farahna M, Bedri S, Khalid S, Idris M, Pillai CR, Khalil EA: Anti-plasmodial effects of Azadirachta indica in experimental cerebral malaria: Apoptosis of cerebellar Purkinje cells of mice as a marker. N Am J Med Sci 2010, 2:518-525

17. Duque V, Seixas D, Ventura C, Da CS, Melico-Silvestre A: Plasmodium falciparum malaria, bilateral sixth cranial nerve palsy and delayed cerebellar ataxia. J Infect Dev Ctries 2012, 6:290-294

18. Potter S, Chan-Ling T, Ball HJ, Mansour H, Mitchell A, Maluish L, Hunt NH: Perforin mediated apoptosis of cerebral microvascular endothelial cells during experimental cerebral malaria. Int J Parasitol 2006, 36:485-496.

19. Potter SM, Chan-Ling T, Rosinova E, Ball HJ, Mitchell AJ, Hunt NH: A role for Fas-Fas ligand interactions during the late-stage neuropathological processes of experimental cerebral malaria. J Neuroimmunol 2006, 173:96-107.

20. Wiese L, Kurtzhals JA, Penkowa M: Neuronal apoptosis, metallothionein expression and proinflammatory responses during cerebral malaria in mice. Exp Neurol 2006, 200:216-226.

21. Schmutzhard J, Kositz CH, Glueckert R, Schmutzhard E, Schrott-Fischer A, Lackner P: Apoptosis of the fibrocytes type 1 in the spiral ligament and blood labyrinth barrier disturbance cause hearing impairment in murine cerebral malaria. Malar J 2012, 11:30

22. Mackintosh CL, Beeson JG, Marsh K: Clinical features and pathogenesis of severe malaria. Trends Parasitol 2004, 20:597-603.

23. Medana IM, Idro R, Newton CR: Axonal and astrocyte injury markers in the cerebrospinal fluid of Kenyan children with severe malaria. J Neuro/ Sci 2007, 258:93-98.

24. Newton PN, Green MD, Mildenhall DC, Plancon A, Nettey H, Nyadong L, Hostetler DM, Swamidoss I, Harris GA, Powell K, Timmermans AE, Amin AA Opuni SK, Barbereau S, Faurant C, Soong RC, Faure K, Thevanayagam J, Fernandes P, Kaur H, Angus B, Stepniewska K, Guerin PJ, Fernandez FM: Poor quality vital anti-malarials in Africa - an urgent neglected public health priority. Malar J 2011, 10:352.

25. Cheeseman IH, Miller BA, Nair S, Nkhoma S, Tan A, Tan JC, Al SS, Phyo AP, Moo CL, Lwin KM, McGready R, Ashley E, Imwong M, Stepniewska K, Yi P, Dondorp AM, Mayxay M, Newton PN, White NJ, Nosten F, Ferdig MT, Anderson TJ: A major genome region underlying artemisinin resistance in malaria. Science 2012, 336:79-82.

26. Nayyar GM, Breman JG, Newton PN, Herrington J: Poor-quality antimalarial drugs in southeast Asia and sub-Saharan Africa. Lancet Infect Dis 2012, 12:488-496

27. Ekanem OJ: Has Azadirachta indica (Dogonyaro) any anti-malarial activity? Niger Med J 1978, 8:8-11.

28. El Tahir A, Satti GM, Khalid SA: Antiplasmodial activity of selected Sudanese medicinal plants with emphasis on Maytenus senegalensis (Lam.) Exell. J Ethnopharmacol 1999, 64:227-233.

29. Hashmat I, Azad H, Ahmed A: Neem (Azadirachta indica A. Juss) - A nature's drugstore: an overview. Int Res J Biol Sci 2012, 1:76-79.

30. Dike IP, Obembe OO, Adebiyi FE: Ethnobotanical survey for potential antimalarial plants in south-western Nigeria. J Ethnopharmacol 2012, 144:618-626.

31. Belayneh A, Asfaw Z, Demissew S, Bussa NF: Medicinal plants potential and use by pastoral and agro-pastoral communities in Erer Valley of Babile Wereda, Eastern Ethiopia. J Ethnobiol Ethnomed 2012, 8:42.

32. Obaseki O, Fadunsin J: The antimalarial activity of Azadirachta indica. Fitoterapia 1986, 57:247-251.

33. Khalid SA, Duddeck H, Gonzalez-Sierra M: Isolation and characterization of an antimalarial agent of the neem tree Azadirachta indica. J Nat Prod 1989, 52:922-926.
34. Isah $A B$, Ibrahim YK, Iwalewa EO: Evaluation of the antimalarial properties and standardization of tablets of Azadirachta indica (Meliaceae) in mice. Phytother Res 2003, 17:807-810.

35. Udeinya Jl, Shu EN, Quakyi I, Ajayi FO: An antimalarial neem leaf extract has both schizonticidal and gametocytocidal activities. Am J Ther 2008, 15:108-110.

36. Lucantoni L, Yerbanga RS, Lupidi G, Pasqualini L, Esposito F, Habluetzel A: Transmission blocking activity of a standardized neem (Azadirachta indica) seed extract on the rodent malaria parasite Plasmodium berghei in its vector Anopheles stephensi. Malar J 2010, 9:66.

37. de Miranda AS, Brant F, Machado FS, Rachid MA, Teixeira AL: Improving cognitive outcome in cerebral malaria: insights from clinical and experimental research. Cent Nerv Syst Agents Med Chem 2011, 11:285-295.

38. Highley JR, Walker MA, McDonald B, Crow TJ, Esiri MM: Size of hippocampal pyramidal neurons in schizophrenia. Br J Psychiatry 2003, 183:414-417.

39. Basir R, Rahiman SF, Hasballah K, Chong W, Talib H, Yam M, Jabbarzare M, Tie T, Othman F, Moklas M, Abdullah W, Ahmad Z: Plasmodium berghei ANKA infection in ICR mice as a model of cerebral malaria. Iran J Parasitol 2012, 7:62-74.

40. Lekic T, Rolland W, Manaenko A, Krafft PR, Kamper JE, Suzuki H, Hartman RE, Tang J, Zhang JH: Evaluation of the hematoma consequences, neurobehavioral profiles, and histopathology in a rat model of pontine hemorrhage. J Neurosurg 2013, 118:465-477.

41. Spriet A, Beiler $D$ : When can 'non significantly different' treatments be considered as 'equivalent'? Br J Clin Pharmacol 1979, 7:623-624.

42. Hunt NH, Golenser J, Chan-Ling T, Parekh S, Rae C, Potter S, Medana IM, Miu J, Ball HJ: Immunopathogenesis of cerebral malaria. Int J Parasitol 2006, 36:569-582.

43. Alvarez S, Blanco A, Fresno M, Munoz-Fernandez MA: TNF-alpha contributes to caspase-3 independent apoptosis in neuroblastoma cells: role of NFAT. PLoS One 2011, 6:e16100.

44. Bienvenu AL, Gonzalez-Rey E, Picot S: Apoptosis induced by parasitic diseases. Parasit Vectors 2010, 3:106

45. Yanpallewar S, Rai S, Kumar M, Chauhan S, Acharya SB: Neuroprotective effect of Azadirachta indica on cerebral post-ischemic reperfusion and hypoperfusion in rats. Life Sci 2005, 76:1325-1338.

46. Vaibhav K, Shrivastava P, Khan A, Javed H, Tabassum R, Ahmed ME, Khan MB, Moshahid KM, Islam F, Ahmad S, Siddiqui MS, Safhi MM, Islam F: Azadirachta indica mitigates behavioral impairments, oxidative damage, histological alterations and apoptosis in focal cerebral ischemiareperfusion model of rats. Neurol Sci 2013, 34(8):1321-1330.

47. Ibezim EC, Odo U: Current trends in malarial chemotherapy. Afr J Biotechnol 2008, 7:349-356.

48. Khalid SA, Farouk A, Geary TG, Jensen JB: Potential antimalarial candidates from African plants: and in vitro approach using Plasmodium falciparum. JEthnopharmacol 1986, 15:201-209.

doi:10.1186/1475-2875-12-298

Cite this article as: Bedri et al: Azadirachta indica ethanolic extract protects neurons from apoptosis and mitigates brain swelling in experimental cerebral malaria. Malaria Journal 2013 12:298.

\section{Submit your next manuscript to BioMed Central and take full advantage of:}

- Convenient online submission

- Thorough peer review

- No space constraints or color figure charges

- Immediate publication on acceptance

- Inclusion in PubMed, CAS, Scopus and Google Scholar

- Research which is freely available for redistribution 